Volume 1, Number 1, January 2019

\title{
Original article \\ Study on Community awareness regarding psychological violence against women
}

\author{
Afroza Begum¹, Farzana Arzu Khan², Ashfia Saberin ${ }^{3}$, Tanmoy Sarker ${ }^{4}$, Rezwana Parveen ${ }^{5}$, \\ Jannatul Ferdous ${ }^{6}$.
}

\begin{abstract}
:
A community based cross-sectional study was carried out in a selected village of Dhamrai, Dhaka with a sample size of 191 to explore the status of community awareness regarding psychological violence against women (PVAW) among respondents $>18$ years of age with a semi-structured questionnaire employing purposive sampling method; data was collected by face to face interview. Female respondent were higher $(51.8 \%)$ in number. This study found that $26.2 \%$ and $29.3 \%$ respondents were in the age group between 28-37 years and 38-47 years respectively (Mean $\pm \mathrm{SD}=37.35$ \pm 11.95 years). Most of the respondents were married (86.4\%); mean duration of marriage was $18.41 \pm 10.438$ years. The mean monthly family income was $21989.53 \pm 12391.419 \mathrm{Tk}$, This study found that nuclear family $(58.1 \%)$ was higher. The findings of the current study shows that $57.6 \%$ respondents have average $(30 \%$ to $<60 \%)$ knowledge regarding psychological violence. Association between the psychological violence with educational status of the respondents was statistically significant. $(\mathrm{p}=.018)$, also there is statistical significant association between psychological violence with family income of the respondents. $(\mathrm{p}=.018)$ and psychological violence with the type of family of the respondents. $(\mathrm{p}=.033)$. Violence against women is a burning public health issue and a serious threat to human rights. Intervention like social awareness programmes can be arranged to improve the knowledge and awareness of the community people.
\end{abstract}

\section{Key words: Community awareness, Psychological violence against women.}

\section{Introduction}

Violence against women (VAW) is a worldwide epidemic; around 1 in every 3 women has experienced it in any form in her lifetime. It exists beyond cultural, geographical, religious, social and economic context all over the world. ${ }^{1}$

Moreover in our country context, there is a social taboo regarding VAW which is culturally acceptable to both party. And the fact is, this taboo complicating the situation more and make the women more vulnerable to violence. Things that can help women is awareness and education regarding violence. According to a study conducted in the year 1999, World-wide researchers considered psychological violence to be a consequence of other forms of violence $^{2}$ specifically physical and sexual violence. ${ }^{3}$

According to WHO world report on violence and health 2002 , violence against women is subdivided under three distinct form named self-directed, Interpersonal and collective. ${ }^{4}$
Self-directed violence again subdivided into two parts, they are suicidal behavior and self-harm. Interpersonal violence subdivided into family/partner violence and community violence. And last one is collective form of violence against women in the social, political and economic sphere of life. ${ }^{5}$

Psychological, mental, or emotional violence describe acts such as prohibiting a woman from seeing her family and friends, repeated insult or humiliation, economic restrictions, harm or threats against cherished objects and other forms of restriction and controlling behaviors. It is difficult to define and determine the psychological violence as it can't be seen or measured, moreover it can take various form. ${ }^{6}$

Now, it is confirmed that psychological violence is a common and remarkable form of interpersonal violence in terms of its frequency, and it's short and long term consequences. ${ }^{7}$ However, there are several argument that

1. Professor and Head, Department of Maternal and Child Health, National Institute of Preventive and Social Medicine (NIPSOM)

2. Medical Officer, OGSB Hospital, Dhaka

3. Medical Officer, Civil Surgeon Office, Bogura

4. Medical Officer, Dental Unit, Rajshahi Medical College \& Hospital

5. Medical Officer, Sararchar Sub-center Bajitpur Upozilla Health Complex, Kishorgonj

6. Medical Officer, Rushmono Specialized Hospital, Dhaka

\section{Address of correspondence:}

Prof. Afroza Begum, Head of the department, Department of Maternal and Child Health, National Institute of Preventive and Social Medicine (NIPSOM) 
victims experience greater trauma, from ongoing, severe psychological violence than from experiencing infrequent physical assault. ${ }^{8}$

Psychological violence against married women is extremely common and persistently practiced by their husbands in Bangladesh, as over $80 \%$ have ever experienced it in their life time with $72 \%$ in the past 12 months. The prevalence seems slightly higher in rural areas than urban. Insulting is the most commonly reported act as $27 \%$ of women ever experienced and over $18 \%$ experienced more than twice in the past 12 months. This is followed by humiliation in front of other and verbal threatening, both of which were ever experienced by $16 \%$ of the women. ${ }^{1}$

\section{Materials and methods:}

A community based cross-sectional study was carried out in a selected village of Dhamrai upazilla, Dhaka, Bangladesh with a sample size of 191 to explore the status of community awareness regarding psychological violence against women (PVAW) among community people aged over 18 years. A semi-structured questionnaire was used and the sampling method was purposive; data was collected by face to face interview. Descriptive and inferential statistics were used in analyzing the data by SPSS software version 25.0 .

\section{Result:}

The current descriptive type of cross sectional study was conducted to explore the community awareness regarding psychological violence against women. A total 191 respondents were interviewed. Female respondents (51.8\%) were higher than male respondent (48.2\%). This study found that $26.2 \%$ and $29.3 \%$ respondents were in the age group between 28-37 years and 38-47 years respectively (Mean $\pm \mathrm{SD}=37.35 \pm 11.95$ years). Most of the respondents were married $(86.4 \%) ; 36.6 \%$ respondents were married for 13-24 years group with mean duration of marriage for $18.41 \pm 10.438$ years. The mean monthly family income was $21989.53 \pm 12391.419 \mathrm{Tk}$, This study found that nuclear family type $(58.1 \%)$ was higher than the joint family type (42.9\%). The findings of the current study shows that $57.6 \%$ respondents have average $(30 \%$ to $<60 \%$ ) knowledge regarding psychological violence.

Table 2 depicts that association between the psychological violence with educational status of the respondents is statistically significant. $(p=.018)$. Table 3 shows that there is statistical significant association between psychological violence with family income of the respondents. $(p=.018)$ Table 4 shows that there is association between psychological violence with the type of family of the respondents. $(p=.033)$

Table 1: Socio-demographic characteristics of the respondent by sex

\begin{tabular}{c|c|c|c}
\hline Characteristics & $\begin{array}{c}\text { Male (92) } \\
\mathbf{4 8 . 2} \%\end{array}$ & $\begin{array}{c}\text { Female (99) } \\
\mathbf{5 1 . 8 \%}\end{array}$ & $\begin{array}{c}\text { Total (191) } \\
\mathbf{1 0 0} \%\end{array}$ \\
\hline \multicolumn{4}{|c}{ Education } \\
Illiterate & $10(10.9 \%)$ & $11(11.1 \%)$ & $21(22 \%)$ \\
Primary & $11(12 \%)$ & $11(11.1 \%)$ & $22(23.1)$ \\
SSC & $44(47.8 \%)$ & $59(59.6 \%)$ & $103(107.4)$ \\
HSC & $16(17.4 \%)$ & $8(8.1 \%)$ & $24(25.5 \%)$ \\
Graduation and & $11(12.0 \%)$ & $10(10.1 \%)$ & $21(22.1 \%)$ \\
above & Occupation \\
Housewife & --- & $81(81.8 \%)$ \\
Service & $19(20.7 \%)$ & --- & \\
Business & 37 & 2 \\
student & 2 & 7 \\
others & 34 & 9 \\
Nuclear & 64 & 47 \\
Joint & 28 & 52 \\
\hline
\end{tabular}

Table 2: Association between psychological violence with educational status of the respondents

\begin{tabular}{|c|c|c|c|c|c|}
\hline \multirow{2}{*}{$\begin{array}{l}\text { Distribution Of All Psychological } \\
\text { Violence scoring in category }\end{array}$} & \multicolumn{3}{|c|}{$\begin{array}{l}\text { \% within Distribution of the respondents according } \\
\text { to family income category }\end{array}$} & \multirow[t]{2}{*}{ df } & \multirow[t]{2}{*}{ p value } \\
\hline & $1000-10000 \mathrm{Tk}$. & $10001-20000 \mathrm{Tk}$ & $>20001 \mathrm{Tk}$ & & \\
\hline$<30 \%$ & $54.1 \%$ & $37.9 \%$ & $22.4 \%$ & & \\
\hline $30 \%$ to $<60 \%$ & $40.5 \%$ & $57.5 \%$ & $67.2 \%$ & 4 & .018 \\
\hline$>60 \%$ & $5.4 \%$ & $4.6 \%$ & $10.4 \%$ & & \\
\hline
\end{tabular}


Volume 1, Number 1, January 2019

Table 3: Association between psychological violence with family income of the respondents

\begin{tabular}{|c|c|c|c|c|c|c|c|}
\hline \multirow{2}{*}{$\begin{array}{l}\text { Distribution Of All Psychological Violence } \\
\text { scoring in category }\end{array}$} & \multicolumn{5}{|c|}{$\begin{array}{l}\text { \% within Distribution of the respondents } \\
\text { according to educational status category }\end{array}$} & \multirow{2}{*}{ df } & \multirow{2}{*}{ p value } \\
\hline & Illiterate & Primary & $\mathrm{SSC}$ & $\mathrm{HSC}$ & $\begin{array}{l}\text { Graduation } \\
\text { and above }\end{array}$ & & \\
\hline$<30 \%$ & $57.1 \%$ & $42.9 \%$ & $30.9 \%$ & $25 \%$ & $14.3 \%$ & & \\
\hline $30 \%$ to $<60 \%$ & $42.9 \%$ & $45.7 \%$ & $67.3 \%$ & $66.7 \%$ & $76.2 \%$ & 8 & .018 \\
\hline$\geq 60 \%$ & $0.0 \%$ & $11.4 \%$ & $1.8 \%$ & $8.3 \%$ & $9.5 \%$ & & \\
\hline
\end{tabular}

Table 4: Association between psychological violence with the type of family of the respondents

\begin{tabular}{|c|c|c|c|c|}
\hline \multirow{2}{*}{$\begin{array}{c}\text { Distribution Of All Scoring of psychological } \\
\text { violence in category }\end{array}$} & \multicolumn{2}{|c|}{$\begin{array}{l}\text { \% within Distribution of the respondents } \\
\text { according to type of family category }\end{array}$} & \multirow{2}{*}{ df } & \multirow{2}{*}{$\begin{array}{c}\mathbf{p} \\
\text { value }\end{array}$} \\
\hline & Nuclear & Joint & & \\
\hline$<30 \%$ & $41.4 \%$ & $27.5 \%$ & & \\
\hline $30 \%$ to $<60 \%$ & $55.0 \%$ & $61.2 \%$ & 2 & .033 \\
\hline$\geq 60 \%$ & $3.6 \%$ & $11.2 \%$ & & \\
\hline
\end{tabular}

\section{Level of knowledge}

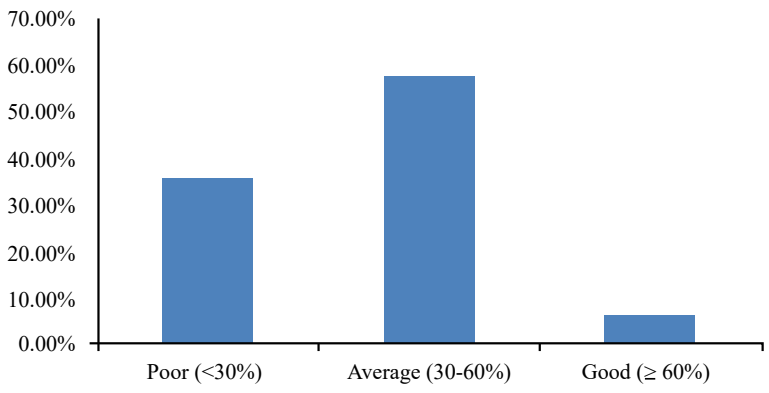

Fig1: Distribution of the respondents by level of knowledge regarding psychological violence

\section{Discussion}

This research aimed to explore the level of community awareness regarding violence against women. In the present research a sample size consisting of 191 adult community people was interviewed. This research is unique in nature as it is done to find out the awareness about violence against women within the community of Bangladesh, where discussion on such topics is not normal.

Among the respondents in the current study, female were more $(51.8 \%)$, majority of the respondents were $(38-47)$ years old of age. This finding is consistent with previous study. According to the present study most of them were muslims and this finding is consistent with previous study. In the study most of the respondents were married with duration (13-24) years. This finding was not consistent with the previous study. In the study majority of the respondents completed primary education and majority of the respondents was housewife followed by businessman and other services. ${ }^{9}$

Our study shows no significant association between gender and knowledge of psychological violence which is not consistent with previous study where knowledge was found to be higher among female participants. This discrepancy could be due to higher number of female participants. $^{10}$

According to this study a wide range of socio-demographic factors has a significant relationship with the knowledge of the respondents regarding violence against women and among the respondents living in nuclear family had average level of knowledge on psychological violence. Almost similar relationship was observed in a study conducted in Shahroud, in northeast of Iran in $2010 .^{11}$

In case of respondents living in joint family had average level of knowledge on psychological violence. Category of the family of respondent was found to be significantly associated with the knowledge of psychological violence. Similar findings were observed in a study in 2008 in Philippines. $^{12}$

Our study shows that the respondents with family with low income had strong statistical association with poor knowledge on psychological violence and is supported by a study conducted by a study conducted in United States in the year $1999 .{ }^{13}$

\section{Conclusion:}

Violence against women is a burning public health issue and a serious threat to human rights. A wide range of sociodemographic factors has a significant relationship with the knowledge of the respondents regarding this issue. Intervention like social awareness programmes can be arranged to improve the knowledge and awareness of the community people. 
Volume 1, Number 1, January 2019

\section{Reference:}

1. Hossen Md. A, Measuring Gender-based Violence: Results of the Violence Against Women (VAW) Survey in Bangladesh, 2014.

2. Garbarino, J. "Future directions." In Children at Risk: An Evaluation of Factors Contributing to Child Abuse and Neglect. Edited by R.T. Ammerman and M. Hersen. New York: Plenum Press, 1990.

3. Arias, J. and K.T. Pape. "Psychological abuse: Implications for adjustment and commitment to leave violent partners," Violence and Victims 14 (1999): 55-67.

4. World Health Organization Geneva 2002. World report on violence and health: summary. Available from: URL: https://www.who.int/ violence injury_prevention/violence/world_report/en/summary_en.pdf

5. Violence prevention alliance. Definition and typology of violence. Available from: URL: https:/www.who.int/violenceprevention/approach/definition/en/

6. Thompson, Anne E.; Kaplan, Carole A. (February 1996). "Childhood emotional abuse”. The British Journal of Psychiatry. 168 (2): $143-148$.

7. Tomison, A.M. and J. Tucci. Emotional Abuse: The Hidden Form of Maltreatment.

8. Sackett, L. A., and D. G. Saunders. "The impact of different forms of psychological abuse on battered women," Violence and Victims 14 (1999): 105-117

9. Khatun, T., \& Rahman, K. F. (2012). Domestic violence against women in Bangladesh: Analysis from a socio-legal perspective. Bangladesh e-Journal of Sociology, 9 (2): 19-29.

10. Mozhdeh Zarei, Masoud Rasolabadi, Fardin Gharibi, and Jamal Seidi. The prevalence of violence against women and some related factors in Sanandaj city (Iran) in 2015; Electron Physician. 2017 Nov; 9(11): 5746-5753.

11. HajianS, Vakilian K, Najm-abadi KM, Hajian P, and Jalalian M. Violence against Women by Their Intimate Partners in Shahroud in Northeastern Region of Iran; Glob J Health Sci. 2014 May; 6(3): $117-130$.

12. Antai D, Oke A, Braithwaite P, and Bryan G. The Effect of Economic, Physical, and Psychological Abuse on Mental Health: A Population-Based Study of Women in the Philippines; Int J Family Med. 2014; 2014: 852317.

13. Hill TD, Krysia N. Mossakowski, and Ronald J. Angel. Relationship Violence and Psychological Distress Among Low-income Urban Women; J Urban Health. 2007 Jul; 84(4): 537-551. 